\title{
Unverheiratete sterben früher an Krebs
}

\section{Hat sich die Überlebensrate Krebs- kranker in den letzten $\mathbf{4 0}$ Jahren verändert, und wenn ja, wie? Diese Frage stellten sich Forscher der Uni- versität Oslo. In ihre Überlegungen bezogen sie den Familienstand mit ein.}

- Ausgewertet wurden die Daten von 440000 Krebskranken. Diese waren in den Jahren von 1970-2007 an Krebs erkrankt. Das Erkrankungsalter reichte von 30 bis zu 89 Jahren. Mit ZeitrisikoRegressionsmodellen konnten mehr als 200000 Krebstote analysiert werden. Dabei konnte zwischen verheirateten, unverheirateten, geschiedenen, getrennt lebenden oder verwitweten Menschen unterschieden werden.

Demnach haben Unverheiratete ein höheres Sterblichkeitsrisiko - unabhängig von Alter, Bildung, Lage des Tumors, dem Zeitpunkt seiner Diagnose und dem Krebsstadium. Die Sterbequote für ledige Männer im Vergleich mit Verheirateten stieg von 18 auf $35 \%$. Bei den ledigen Frauen nahm die Sterberate auf $22 \% \mathrm{zu}$, von $17 \%$ bei den Verheirateten.

\section{Kommentar}

Eine Ehe schützt offenbar in guten wie in schlechten Zeiten. Krebskranke Ehepartner überleben ihr Tumorleiden länger. Eine Erklärung gibt es dafür nicht. Möglich wäre es, dass der Verheiratete zum Zeitpunkt der Diagnose in einer besseren körperlichen Verfassung ist und auf die Behandlung besser anspricht.

K. MALBERG

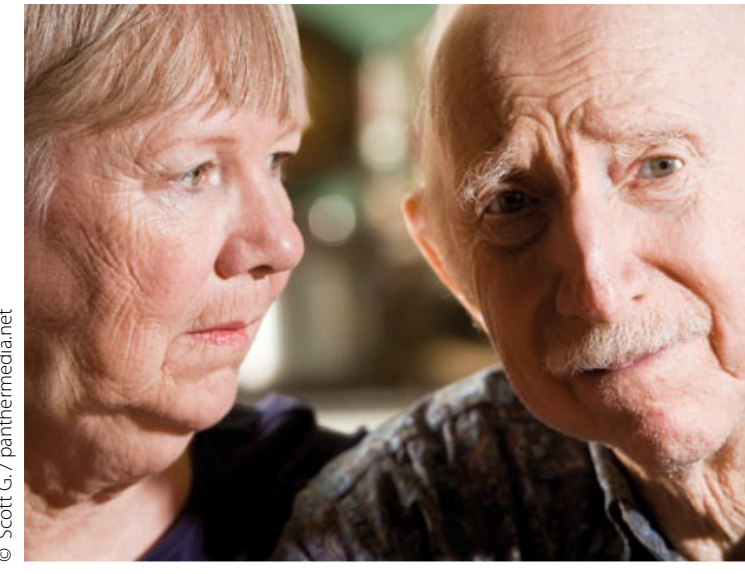

Warum korreliert die Krebssterblichkeit mit dem Familienstand?

- H. Kravdal, A. Syse

(Univ.of Oslo, Boks 1072, Blindern Norvay: E-mail:hakon.kravdal@studmed.no) Changes over time in the effect of marital status on cancer survival. Published on 14 Oct in BMC Public Health 2011; 11: 804; doi: 10.1186/ 14712458-11-804 